\title{
La Constitución cubana de 2019 en perspectiva histórica e ideológica: Aproximaciones a su sistema político electoral
}

\author{
The Cuban Constitution of 2019 in historical and ideological perspective: \\ Approximations to its political electoral system
}

\author{
Harold Bertot Triana (iD \\ Universidad de La Habana, Cuba
}

\begin{abstract}
RESUMEN El artículo analiza la Constitución cubana de 2019 desde una perspectiva histórica e ideológica con especial énfasis en su sistema político electoral. Después de brindar los fundamentos políticos e ideológicos de los modelos socialistas de Europa del Este en el siglo XX, pasa a caracterizar el modelo político electoral establecido en la Constitución cubana de 1976 como parte de una continuidad para valorar la Constitución actual en términos de continuidad o ruptura.
\end{abstract}

PALABRAS CLAVE Constitución cubana de 1976, Constitución cubana de 2019, modelo político electoral, Estado, ruptura, continuidad.

ABSTRACT The article analyzes from a historical and ideological perspective the Cuban Constitution of 2019, with special emphasis on its political electoral system. After providing the political and ideological foundations of the socialist models of Eastern Europe in the twentieth century, the article goes on to characterize the political electoral model established in the 1976 Cuban Constitution as part of a continuity, to then assess the current Constitution of 2019 in terms of continuity or rupture.

KEYWORDS Cuban Constitution of 1976, Cuban Constitution of 2019, political electoral model, State, rupture, continuity. 


\section{Introducción}

Con la aprobación en referéndum popular de la Constitución cubana el 24 de febrero de 2019 (Cubadebate, 2019) ${ }^{1}$ y su proclamación el 10 de abril del mismo año, se configura un hecho importante en la historia de Cuba desde que comenzó el periodo revolucionario el 1 de enero de 1959. Así, se deroga la Constitución de 1976, nacida en un contexto interno e internacional muy diferente al que tenemos hoy, con una clara intención de reactualizar el ordenamiento jurídico hacia los importantes cambios económicos y sociales acontecidos en Cuba durante más de cuarenta años.

El modelo político cubano de la Constitución de 1976 tuvo una fuerte influencia de los fundamentos y las características de una concepción sobre el poder y la organización política de los modelos alternativos al capitalismo de finales del siglo XIX y principios del siglo XX, de los países del llamado «socialismo real» de Europa del Este. Se puede afirmar que su influencia fue incluso más fuerte que la larga tradición constitucionalista cubana del siglo XIX y el pensamiento político más avanzado del siglo XX en Cuba. Este antecedente es un hecho que en ocasiones pasa inadvertido para algunos estudiosos, que en la definición de las características, ventajas o limitaciones del modelo político cubano actual han estado ausentes de identificar, ante todo, el contexto histórico en que se fue construyendo esta experiencia en la masa continental euroasiática, los móviles políticos y los matices de sus fundamentos teóricos e ideológicos que constituyeron las rasgos característicos de su organización y funcionamiento.

En este trabajo se analizará el modelo político que se establece en la Constitución cubana de 2019 en comparación con el modelo anterior regulado en la Constitución de 1976. El énfasis estará en la dimensión histórica e ideológica del tipo de modelo establecido en la Constitución de 1976, ya que nos pone en mejores condiciones de valorar, caracterizar y enjuiciar los cambios que se proyectan en las estructuras políticas del poder en Cuba y supone una ruptura o continuidad de los principios estructurales en la organización política y del ejercicio del poder. Para esto, el trabajo abordará los fundamentos políticos e ideológicos de los modelos socialistas de Europa del Este considerando que constituyeron los soportes fundamentales que inspiraron el modelo político cubano vigente. En segundo lugar, brindaremos una caracterización del modelo político cubano establecido en la vigente Constitución de 1976, y finalizaremos con una valoración sobre la repercusión de los cambios que se proyectan en la nueva Constitución para el modelo político electoral.

\footnotetext{
1. El informe de la Comisión Electoral Nacional sobre los resultados finales de la votación del referendo constitucional del 24 de febrero del 2019 arrojó que de los 8 millones 705 mil 723 electores, ejercieron el derecho al voto 7 millones 848 mil 343 electores para el 9o,15\%, de los cuales votaron por el Sí, 6 millones 816 mil 169 electores, que representa el $78,30 \%$ de la lista y el $86,85 \%$ de los electores que votaron. Los votos obtenidos por el No fueron de 706 mil 400 para el 8,11 \% de la lista y el $9 \%$ de los electores que votaron. De igual manera de las 7 millones 848 mil 343 boletas que se depositaron en la urna se declararon válidas por reunir los requisitos establecidos en la Ley, 7 millones 522 mil 569 lo que representa el 95,85\%. Disponible en https://bit.ly/2MfG2RR.
} 


\section{La alternativa política al liberalismo: la construcción de los modelos políticos de los países socialistas de Europa del Este durante el siglo XX}

El punto de partida para los proyectos políticos socialistas en el siglo XX que pusieron desde muy temprano en discusión el tema de la participación de las masas y el control del aparato estatal por el poder popular, lo constituyó el fundamento brindado por Carlos Marx en sus escritos sobre la Comuna de París en 1871 (Marx y Engels, s.f.: 546). Esta perspectiva intentó construir una nueva dimensión social y política a través de un sistema de relaciones sociales y políticas que debía ser contrario a dos puntos sostenidos por la ideología liberal: la concentración del poder político en sectores dominantes de la sociedad, que hacía distante e inaccesible el poder estatal; y una concepción antidemocrática de la vida política, caracterizada por un orden de participación limitado y excluyente. ${ }^{2}$

A principios del siglo XX en Europa, los movimientos de izquierda, fundamentalmente los obreros, encontraron en la experiencia de la Comuna de París y en los consejos de obreros y soldados que se sucedieron en la Revolución rusa de 1905 y 1917, los principios y directrices para construir un modelo de república que fuera capaz de organizar y movilizar políticamente a la masa obrera, articular mecanismos institucionales de mediación política controlados por principios de democracia directa, ampliar la representación política de los obreros en los órganos e instancias de dirección estatal y la realización real y efectiva de derechos ciudadanos. Se pensaba que la Comuna de París había rescatado para la construcción de sus relaciones de poder los perfiles políticos y teóricos de Jean-Jacques Rousseau en el vínculo de la figura del representante y el pueblo, titular de la soberanía indivisible, indelegable e intransferible, con la institucionalización del mandato imperativo. ${ }^{3}$

2. En la perspectiva de Marx, el nuevo modelo no podía contentarse únicamente con poner sobre la mesa un debate circunscrito a las mejores formas o vías de lograr la socialización del poder, a partir de su distribución a amplios sectores de las masas populares, so pena de un futuro inviable, si este no era congruente con la posibilidad de liberar a las masas trabajadoras de la esclavitud del capital, de encontrar modelos con formas de socializar los medios de producción. Por esta razón, Marx no solo encontró en la comuna de París un gobierno de la clase obrera, sino «la forma política al fin descubierta para llevar a cabo dentro de ella la emancipación económica».

3. En estas dimensiones encaminadas a romper las ataduras políticas con respecto al ámbito de «libertad» política, se caracterizó un marco de acción encaminada a eliminar barreras institucionales del ejercicio y responsabilidad directa de todos los ciudadanos en el aparato estatal. Lenin había destacado de la Comuna de París un poder de nuevo tipo basado en las características fundamentales siguientes: la fuente del poder no estaba en una ley previamente discutida y acordada por un parlamento, sino en la iniciativa directa de las masas populares desde abajo y en las localidades, en la «toma» directa del poder; el orden público quedaba bajo el amparo de los propios obreros y campesinos armados, lo que posibilita que se sustituyera a la policía y al ejército como instituciones separadas del pueblo y contrapuestas a él; los funcionarios se someten a un control especial, convertidos en mandatarios elegibles, y removibles en cualquier momento a voluntad del pueblo (Lenin, 1976: 277). En el proyecto de decreto sobre el derecho de revocación, de 19 de noviembre de 1917, Lenin expresó: «Cualquier organismo o asamblea de delegados puede considerarse auténticamente democráticos y verdaderamente representativos de la voluntad pueblo 
Desde entonces, los movimientos revolucionarios de perfiles socialistas basados en el legado de la Comuna de París concibieron que no podían servirse de las viejas instituciones liberales que entendían había servido a la burguesía para parapetarse frente al movimiento obrero. Si el ataque de la Comuna de París había sido directamente hacia los principios institucionales de organización de la vida pública cimentados en los valores e ideología del modelo liberal político, el parlamento se visualizaba como fiel reflejo del excluyente principio de representación inglesa, un símbolo institucional de un modelo político esencialmente mediado por instituciones aristocráticas. Las instancias parlamentarias se vieron como el eje sobre el cual se ordenaba y fraguaba en la vida política un régimen político cuyos principios de integración completaban una lógica de representación únicamente para las clases de mayor fuerza económica. Sus características funcionales se comprendían como complejas relaciones institucionales entre facciones, clases o grupos sociales, cuyo espacio había cerrado las puertas a los obreros.

De este modo, los principios organizativos y orientadores de este nuevo tipo de Estado se entendían novedosos y contrarios al anterior si precisamente lograban articular la vida política con instituciones de democracia directa que pasaban por una relación y responsabilidad de todos los ciudadanos en la «cosa pública». En esta perspectiva estaba la idea de Lenin: «La república parlamentaria burguesa dificulta y ahoga la vida política independiente de las masas, su participación directa en la edificación democrática de todo el estado, de abajo arriba. Los soviets de diputados obreros y soldados hacen lo contrario» (Lenin, 1976b: 292).

En este marco, el principio de unidad de poder signó la construcción de la nueva institucionalidad legada por la Comuna de París. Rechazaba el principio de tripartición de poderes de los Estados nacidos después de la Revolución francesa de 1789, que tuvo como sustento teórico el pensamiento de Montesquieu (1976: 191) sobre la libertad política. Los argumentos en contra de este principio en general se movieron en torno a apuntar el carácter relativo de sus fundamentos, que se atemperaban a las ideas revolucionarias que combatieron el poder absoluto de la feudalidad, y al propio escenario político de Inglaterra del siglo XVIII, donde se subraya la base social y el componente clasista que animó la tesis de la tripartición de poderes. Como expresó Ferrando Barría: «Si Rousseau juzgó al ciudadano juez final de la actuación política, Montesquieu se preocupó de cómo controlar a los que controlan, mediante un intento de equilibrio planificado de los grupos en el poder» (Ferrando Badía, 1989: 72).

De este modo, la unidad de poder devino para la posteridad en un símbolo de una manera de pensar una institucionalidad alternativa a los rasgos del parlamentarismo. El principio condujo implícitamente al reconocimiento, en un orden jerárquico, a la importancia y trascendencia para una verdadera democratización de la vida pública de los órganos de mayor expresión de la soberanía popular con la negación de que otros órganos, sin esa representación soberana, pudieran controlar o enmendar sus deci-

solo en el caso de que se reconozca y ejerza el derecho de revocación de los elegidos por los electores» (Lenin, 1977: 422). 
siones. Por esta razón, en un mismo sistema de órganos de poder se tornó imposible otorgar prerrogativas a órganos diferentes dentro de la misma estructura, que pudieran hacer nulas decisiones de los órganos expresivos del único poder que se reconocía: el poder de las masas, de la mayoría organizada políticamente (Bertot Triana, 2014: 94).

Sin embargo, es destacable apuntar que la construcción de un modelo político bajo el principio de unidad de poder siempre estuvo asociada en sus orígenes a la construcción de un diseño político matizado por la urgencia y premura de decidir y ejecutar tareas de transformación revolucionaria, en la medida que se tornaba condición indispensable la existencia de órganos e instituciones caracterizadas por una unidad política e ideológica en su componente social. Esa fue una de las razones -al menos en su actividad práctica inmediata- para concentrar en un mismo órgano las facultades de legislar y ejecutar, como sucedió con los soviets (consejos de obreros que pasaron a ser órganos del nuevo Estado) en la experiencia revolucionaria rusa de principios del siglo XX. Esta idea estaba presente en Lenin cuando vio en los soviets «la posibilidad de conjugar las ventajas del parlamentarismo con las ventajas de la democracia inmediata y directa», es decir, de «recurrir en la misma persona de los representantes elegidos por el pueblo la función legislativa y la ejecución de las leyes» (Lenin, 1964: 34).

En este sentido, la unidad de poder, si bien no se identificó con unidad de funciones, nació con la intención de concentrar en una unidad de acciones ideológicas homogéneas las políticas inmediatas de la clase mayoritaria en torno a sus necesidades e intereses en las tareas de transformación. Por ello considero que la unidad de poder en sus orígenes, y como luego se establecería en muchas constituciones del antiguo campo socialista, estuvo marcada por una unidad estructural de acción política entre todos los órganos del aparato de poder. El más claro ejemplo de los rasgos y características que asumió este tipo de modelo político lo marcó la Unión Soviética, que tendría un influjo directo en el modelo político cubano que se consagró en la Constitución de 1976, sobre todo de la Constitución soviética de 1936. De modo general, en las constituciones de 1917, 1924, 1936 y 1977, se definió precisamente un sistema político bajo moldes institucionales que rechazaron los principios organizativos y funcionales del Estado burgués nacido en 1789 (Grigorián y Dolgopólov, 1979: 391-40o). ${ }^{4}$ El mecanismo de poder no se construyó a partir de fragmentar el sistema de órganos del aparato estatal con el reconocimiento de prerrogativas en alguno de ellos como contrapeso frente al resto, sino que se potenció un modelo asambleario para vertebrarlo en un sistema único de órganos, cuyas tareas en todos sus eslabones asumieron funciones legislativas y ejecutivas. ${ }^{5}$

4. Sobre las particularidades del modelo político soviético existe una amplia literatura soviética. Ver los autores citados como referencia.

5. En el escalón más alto del sistema de órgano de poder se encontró el Soviet Supremo de la Unión Soviética, dividido en dos cámaras -el Soviet de la Unión y el Soviet de las Nacionalidades, que desde su seno se constituía el Presídium del Soviet Supremo de la Unión Soviética, como un órgano permanente de este, elegido en sesión conjunta de sus cámaras. En general, los rasgos del sistema soviético estuvieron marcados por la estructuración política de los mecanismos de poder del Estado bajo el principio rector del centralismo democrático en los siguientes términos: se definió la organización y la actividad de los 
Desde el punto de vista ideológico, las constituciones soviéticas de 1936 y 1977 tendieron a consagrar en sus regulaciones fases superiores en el desarrollo hacia una sociedad comunista sin clases sociales, y al reino de la "autogestión social», cuyas etapas precedentes fueron concebidas en un marco ideológico que fundía y relacionaba cada vez en una misma dirección al individuo y al Estado. Este último, pese a estar regulado jurídicamente en sus funciones, atribuciones, competencias y límites en el texto constitucional, entendió su realidad y existencia en el marco de intereses de «todo el pueblo» con una tendencia a entender válidos todos los actos de un Estado antes que imponerle límites en un documento jurídico y político, que a su vez se entendía como el reflejo de su realidad.

Sobre esto hay que entender que el sistema de órganos de poder soviético se construyó como resultas de un poder constituyente que tomaba expresión en el propio hecho revolucionario. La importancia y las funciones asumidas por el máximo órgano de poder, el Soviet Supremo del Pueblo como poder constituido y constituyente, significó para el pensamiento político una forma de construir una nueva institucionalidad al margen de la doctrina del "poder constituyente» de los modelos demoliberales, que concibe la existencia de un órgano independiente. En este sentido, para las fuerzas revolucionarias la Constitución pasaba a concebirse como su producto histórico sin necesidad de un poder constituyente independiente, razón por la cual desde esa posición singular de la soberanía popular en el máximo órgano de poder del Estado las propias leyes dictadas por ella en la construcción de una sociedad superior se veían como su último producto histórico.

En este sentido, hubo una negación rotunda y absoluta de un modelo político montado en la desconcentración de poderes, que en el fondo impidió asimilar y desarrollar el principio de constitucionalidad (Grigorián y Dolgopólov, 1979: 392) ${ }^{6}$ como un criterio activo en la práctica jurídica socialista. En la doctrina y práctica política soviética,

órganos del Estado, agrupados en un sistema único en los distintos eslabones del aparato estatal, que en la búsqueda de conjugar la realización de la democracia con una dirección centralizada del Estado, caracterizó un sistema de órganos representativos de poder -los soviets de diputados populares- electivos de abajo arriba. Esto era consustancial con una subordinación de los órganos inferiores a los superiores, y mecanismos de control democrático sobre los diputados, obligados a rendir cuenta a los electores y revocados en todo momento. También se manifestó este principio en la organización y funcionamiento de los órganos de justicia, y en todo el sistema del Ministerio Fiscal, que diseñó una estructura de centralización y subordinación a un centro único, el Soviet Supremo de la Unión Soviética. En este contexto, el Partido Comunista de Unión Soviética se convirtió en la fuerza política dirigente de la sociedad soviética para la construcción del comunismo.

6. «La correlación entre la Constitución y la legislación corriente se establece a favor de la primera, es decir, se reconoce su primacía jurídica sobre una ley y, con mayor razón, sobre los demás actos jurídicos. Esto significa que, en caso de una colisión entre las normas constitucionales, por una parte, y las de una ley, decreto, disposición, orden, instrucción, etcétera, por la otra, vencen las primeras. Toda la actividad posterior del Estado en la esfera de creación de normas jurídicas descansa sobre los preceptos constitucionales. Las leyes y otros actos jurídicos deben aprobarse sobre la base y en orden de observancia de la Constitución. Los actos emitidos de otra manera se reconocen nulos jurídicamente». 
el verdadero criterio activo en el funcionamiento del Estado y sus relaciones con los ciudadanos lo alcanzó la expresión normativa en la ley y los criterios y principios que se vertebraron en torno a su observancia, que en cierta medida enrolaron en ella evidentes matices desarrollados por la teoría constitucionalista de Occidente en base a un criterio activo de la Constitución. Esto sirvió para que en la Unión Soviética el marcado interés recayera en un criterio activo del principio de legalidad que sirvió de base para sujetar jurídicamente la actuación de un Estado que se fortalecía y perfeccionaba en bloque (Samoshenko, 1988: 477-491).7 En razón de ello, el modelo soviético, reproducido en la experiencia socialista de Europa del Este, estructuró un sistema de control de los actos de la legalidad en que los tribunales y la procuraduría (Ministerio Fiscal), funcionaban como órganos de control de la legalidad socialista; el Partido Comunista, sin que encontrara regulación legal o constitucional, intervenía en la protección de los derechos ciudadanos, y una protección de carácter judicial y administrativo ante violaciones de la ley o por medidas arbitrarias o improcedentes de los funcionarios de carácter administrativo (Marianetti, 1961: 63-86).

En cuanto al diseño político de los países socialistas de Europa durante el siglo XX, en la lógica de superar el modelo del liberalismo, se evidenciaron dos modelos: uno que lo caracterizó fundamentalmente la negación del pluralismo partidista, como fue el caso del soviético; y en otro la existencia de varios partidos con la asunción del papel rector del Partido Comunista (Peraza Chapeau, 1975: 189-206; Flores Juberías, 1992: 174-175). ${ }^{8}$ En los inicios, se pensó en la construcción de un modelo electoral como mecanismo para romper con una dualidad ínsita en el modelo liberal: la brecha enorme

7. Ver a modo de referencia sobre el tema de la legalidad en la URSS.

8. Ver en relación con las características de los sistemas electorales en estos países. Para algunos autores cabe distinguir cuatro fases sucesivas en la evolución de los procesos electorales en la Unión Soviética y en el resto de los países socialistas: una primera etapa durante los años veinte en la Unión Soviética y a finales de los cuarenta en la Europa del Este, en que las elecciones tendrían lugar en un clima de enfrentamiento político entre las autoridades comunistas y sus opositores locales. En esta etapa se privarían del sufragio a los presuntos enemigos del régimen o se restringiría el secreto del mismo y las campañas electorales se desarrollarían en medio de enfrentamientos rara vez pacíficos. Una segunda etapa marcada por la desaparición de las fuerzas de la contrarrevolución, cuando la Unión Soviética desde finales de los años veinte y el resto del bloque socialista desde comienzos de los años cincuenta comenzaron a desarrollar lo que se ha venido calificando de elecciones «plebiscitarias» $\mathrm{o}$ «aclaratorias». Se caracterizaría por la desaparición de la conflictividad propia de los primeros años de socialismo, y por la implantación de normas procedimentales que permitirían una mayor participación. La tercera fase se corresponde con el periodo conocido como «desestalinización», donde los procesos electorales cobrarían una relevancia mayor. Los soviets y los consejos locales adquirirían nuevos poderes con el fortalecimiento de un sistema de comités y se advierte una mayor diversidad social y unas condiciones pluralistas más sólidas que darían lugar a contiendas electorales en las que el resultado no era siempre enteramente predecible. La cuarta fase de esta evolución se encuadra en las dos últimas décadas de existencia de los países del bloque socialista, en la que no cabe hablar de un desarrollo parejo en los distintos países de la zona ni de una tendencia inequívoca hacia la democratización, pero en la que se advierten tendencias liberalizadoras, como en Polonia cuando la Ley Electoral del 1956 permitió la posibilidad de nominar un número de candidatos superior al de escaños a cubrir, entre otras reformas. 
entre la igualdad formal política y las diferencias materiales de vida entre las distintas clases. Se rechazó abiertamente pensar las relaciones de poder en los moldes de la ideología liberal, en el campo donde precisamente se pensaba se había brindado una concepción abstracta del poder (Sánchez Vázquez, 2006). ${ }^{9}$

Desde entonces, la concepción del Estado y el poder se presentaron con sus nexos y vínculos concretos con intereses y clases específicas. Una ampliación de los derechos electorales a la mayoría pretendía romper con una visión del mundo social y político en esferas contrapuestas, identificadas con lo público y lo privado, a la vez que promover la igualdad política de todos sus miembros en el campo de lo real. La política pasó a representar un campo decisivo para el orden de las nuevas relaciones sociales, donde el proletariado apareció como el sujeto con la misión universal de emancipación de toda la sociedad.

En el caso de la estructuración de un modelo político con la ausencia de partidos en pugna electoral que tuvo como trasfondo la aceptación oficial de la teoría del «Estado de todo el pueblo» en la Unión Soviética, con un influjo directo en la elaboración de las normas y principios constitucionales de los países socialistas, y en el modo en que estos estructuraron las características del modelo electoral, ${ }^{10}$ suplió los mecanismos de un proceso electoral competitivo, por mecanismos políticos de depuración y selección de candidatos. Las propias contradicciones políticas enfrentadas por el proceso soviético explican en un inicio los rasgos excluyentes del proceso revolucionario con respecto a las "clases explotadoras», definidas así por la finalidad de construir una ideológica unitaria para la consolidación del nuevo poder.

Hasta el año 1936, esta política de exclusión había reproducido en sus consecuencias la concepción liberal del sufragio como una función pública, que bajo el liberalismo permitió reducir el censo electoral a aquellas personas con condiciones sociales y/o intelectuales, y cuyo resultado fue el sufragio censitario y capacitario (donde el primero exigía la inclusión en el censo de contribuyentes y el segundo la posesión de algún título académico o de formación intelectual reconocida), mientras que en el nuevo proceso

9. Ver el análisis que realiza sobre el poder.

10. La literatura soviética es vasta en desarrollar la idea del «Estado de todo el pueblo». Ver a modo de referencia a Chejarin (1978: 109-126). En la nueva estructura social, se entendían liquidadas las clases explotadoras, y la sociedad soviética se componía de la clase obrera, los campesinos y los intelectuales, pero ya no en condiciones de lucha, sino en una existencia no antagónica, en estado de alianza y colaboración. La justificación de esta «fraternidad» se explicaba de forma muy sencilla: en el régimen koljosiano, los campesinos dejaron de ser una clase de pequeños productores apegada a su pedazo de tierra y explotada por los terratenientes y kulaks para comenzar a ser un trabajo colectivo basado en la propiedad colectiva. La intelectualidad, por su parte, era nueva, surgida del seno del pueblo difiera socialismo. El proletariado era una clase «emancipada» de toda explotación y ocupaba una posición rectora en la sociedad. En dicha sociedad exenta de contradicciones clasistas, el Estado no representa ya a ninguna clase en particular, ni era más el Estado de la «dictadura del proletariado». Por encima de sus diferencias, dicho aparato representa a cada individuo de la sociedad, para entonces todos trabajadores y ciudadanos. La justificación teórica de su existencia fue sencilla: era el «Estado de todo el pueblo» (Ponomariov, s.f.: 509-519). También ver Balibar (1977: 22-25). 
revolucionario socialista que emergía se excluían por criterio expreso de ser las «clases explotadoras» derribadas del poder (Grigorián y Dolgopólov, 1979: 405).

La naturaleza del sistema electoral se insertó en un modelo de organización política que dio muy pocos espacios a la participación de las fuerzas no orientadas políticamente con la alternativa. El diseño tomó fuerza al comprender distintas posibilidades de acceso a la dirección política a partir de mecanismos depuratorios y de selección, mediado por las estructuras políticas y sociales de un modelo integrado que no daba cabida a la posibilidad de «ruedas no dentadas» en un mecanismo de transformación social. Dicho sistema electoral fue evolucionando hasta consagrar un derecho electoral igual (cada ciudadano tiene un voto y participan sobre bases iguales), con la forma de votar abierta y secretamente. Sin embargo, se establecieron diversas formas de nominar y elegir a los representantes políticos de acuerdo con la jerarquía de los órganos, dirigidas a «una comprobación minuciosa de las cualidades de los representantes electos del pueblo a los órganos de poder» (Grigorián y Dolgopólov, 1979: 405).

Todo esto integró un sistema en torno a las organizaciones políticas y sociales para filtrar a los miembros de la sociedad en el acceso a cargos determinados. En esta relación se definió la operatividad y el funcionamiento del modelo en el papel y la función otorgada al Partido Comunista y su relación con el Estado, al cual se le reconocía, como las formas fundamentales de la dirección política, trazar la línea política, el control de que la política corriente corresponda aquella y la intervención en casos necesarios, así como la organización del sistema de selección y distribución de los cuadros políticos (Grigorián y Dolgopólov, 1979: 369). La dirección del Partido Comunista en este tipo de modelo supuso su participación decisiva en la selección y la distribución de los cuadros dirigentes. Como expresó un teórico soviético, «al igual que cualquier partido gobernante, cuyos representantes obtuvieron la mayoría absoluta de votos y que recibe el número correspondiente de puestos en los organismos representativos, el Partido Comunista forma el gobierno en la sociedad socialista» (Shajnazárov, 1984: 368).

Las candidaturas para ocupar determinados cargos del Estado, bajo la dirección del Partido, evidenciaron fuertemente las estrechas relaciones de este último con el Estado. Esta relación devino muy complicada de explicar tanto en lo que se conoció como teoría del comunismo científico como en la política práctica, y acaparó la atención de los congresos de los partidos comunistas (Shajnazárov, 1984: 357). En este sentido, el papel dirigente del Partido se manifestaba en la elaboración de los principios en que se basa el mecanismo de selección y distribución de los cuadros, la proposición de criterios científicamente fundados con los que era necesario guiarse al designar a los cuadros para cargos de distinto rango y tipo profesional, si bien la designación de los funcionarios en el aparato estatal y económico pertenecía íntegra y completamente a la competencia de los organismos representativos y ejecutivos de poder y de administración. En todo esto:

Las organizaciones del Partido tienen un derecho indiscutible a recomendar, de común acuerdo con los sindicatos, a los órganos de Estado a las personas cuyas candi- 
daturas encuentran apoyo y aprobación en las colectividades respectivas. En este caso, el partido no desempeñaba el papel de mando, sino que actúa como portavoz de la opinión pública, de la voluntad de los trabajadores (Shajnazárov, 1984: 369).

Aunque en la práctica el Partido Comunista tenía mucho más peso en la colocación de las personas en los cargos de poder.

Esta forma de selección y proposición de candidatos, que estaba en correspondencia con la naturaleza y características del propio modelo político, se extendió a varias constituciones y legislaciones en materia electoral del resto de los países del campo socialista en las que el Partido, las organizaciones de masas y las asambleas generales de los trabajadores de las empresas designaban a los candidatos a diputados (Blagojevic y otros, 1971: 202). Si en la Unión Soviética el Partido Comunista participaba en las elecciones con el resto de las organizaciones, en los otros países socialistas los partidos comunistas y de trabajadores participaban integrados en un Frente Popular. Ellos presentaban los candidatos unidos propuestos por los diferentes partidos y las distintas organizaciones sociales en proporción a su importancia numérica y a su asimilación política y social en el país. Todas las organizaciones presentaban a sus candidatos y el conjunto de ciudadanos tenía el derecho de apoyarlos en las reuniones, en la prensa, en la radio, etcétera (Blagojevic y otros, 1971: 203-304).

En la mayor parte de los países socialistas, la circunscripción elegía un solo diputado, con excepción de Polonia y la República Democrática Alemana, donde la circunscripción elegía varios diputados. Sobre este tipo de procesos en estos países, algunos autores escribieron que eran procesos animados, con participación diversa también a través de diferentes medios, pudiendo los trabajadores asignarle tareas concretas a sus representantes (Blagojevic y otros, 1971: 202). Sin embargo, el propio diseño institucional que definió tres orientaciones fundamentales de la dirección de la sociedad por el Partido Comunista, política, ideológica y de organización (Shajnazárov, 1984: 364), conllevó serias limitaciones en el despliegue de un sistema representativo que garantizase la iniciativa, decisión y control de los trabajadores, y de los diferentes sectores de la población, en la selección y distribución de los cargos estatales.

Lo anterior confrontaba con las posibilidades de organización política y administrativa puestas en discusión por varias fuerzas de izquierda en Europa sobre la forma federal o unitaria que debía adoptar el Estado socialista para llevar a cabo las finalidades emancipatorias. Es decir, si la democracia se desplegaría sin la necesidad de establecer estructuras mediadoras entre la masa y sus dirigentes en un Estado unitario, con organismo centrales, o si el Estado debía descentralizarse hasta el extremo contrario. En marxistas y anarquistas se convendría en la necesidad, si bien con diferencia sobre el momento de su desaparición, de no implicar la existencia del Estado en una finalidad en sí misma del proceso revolucionario. Y ello implicaba dimensionar la dilución hacia temas como la relación entre partido y masas, dirigente y dirigidos, y partido y Estado; la centralización o descentralización de las decisiones políticas y económicas; el empoderamiento político y económico del trabajador, etcétera (Leh- 
ning,2004: 21). ${ }^{11}$ Por esa razón autores de disímiles signos ideológicos apuntaron al poco interés que despertaban las elecciones en la Unión Soviética, sobre todo por el papel que desempeñaba el Partido Comunista en la vida de los soviets, y en los propios mecanismos de selección de candidatos al Soviet Supremo (Hill, 1972: 47-67). En buena medida, esta relativa pérdida de autonomía de las organizaciones sociales y el papel dirigente del Partido Comunista en este proceso le valió más de una crítica (Zaslavsky y Brym, 1978: 363-371).

\section{Modelo político electoral cubano (1976-2018)}

La caracterización que hemos desarrollado anteriormente nos pone en mejores condiciones de analizar los fundamentos políticos e ideológicos del modelo político electoral vigente en Cuba en la Constitución de 1976, si tomamos en cuenta que fue un referente indiscutible en su concepción y características. En primer lugar, es importante mencionar que el periodo comprendido entre 1959 y 1976 en Cuba se conoce como «provisionalidad revolucionaria» (Álvarez Tabío, 1988; Azcuy, 2010). ${ }^{12}$ Con el triunfo revolucionario de 1959 que derrocó al presidente Fulgencio Batista, quien había provocado un golpe de Estado en 1952 y había derogado la Constitución de 1940, se puso en vigor la Ley Fundamental de la República, que se inspira en la mencionada Constitución de 1940 pero con cambios importantes. Entre ellos, se atribuye a un Consejo de Ministros la potestad legislativa y constituyente así como todas las facultades que eran del Congreso (compuesto por un Senado y una Cámara de Representantes), además de contemplar la existencia de un presidente de República y un primer ministro (República de Cuba, 1959: artículos 118 y ss.). Durante este periodo no hubo elecciones hasta la institucionalización del Estado socialista en 1976, salvo la conocida «experiencia de Matanzas», donde se realizaron elecciones para constituir los órganos de representación popular que luego se extendieron a todo el país con la aprobación de la Constitución de 1976 (Garcini Guerra, 1974: 61-80).

Después de una historia inicial marcada por enfrentamientos directos con Estados Unidos, la Revolución cubana se alineó abiertamente a finales de los sesenta y principio de los setenta en el campo de los países socialistas liderados por la Unión Soviética, en un mundo escindido en dos grandes polos económicos, políticos y militares después de la Segunda Guerra Mundial, periodo conocido desde entonces como «Guerra Fría». De este modo, la institucionalización del poder revolucionario en Cuba encontró en los principios organizativos y de funcionamiento del sistema soviético el modelo político paradigmático para consagrar el proceso revolucionario, de enorme arraigo e incidencia en la vida social, cultural, política y económica. Con esto se enraizó en la realidad

11. Véase en relación con las discusiones entre el llamado marxismo libertario, de corte anarquista, y las concepciones de Lenin.

12. Véase ambos autores para conocer la perspectiva de los teóricos cubanos en relación con esta aceptación en el orden ideológico. 
cubana una manera de entender una sociedad socialista y se arrastraron todos los vicios del modelo soviético, caracterizado por una excesiva centralidad del Estado en todas las esferas de la vida social y económica, del mismo modo que en el orden constitucional había vertebrado una institucionalidad caracterizada por una subestimación de los derechos y garantías formales ciudadanas frente al Estado, carentes de mecanismos reales de participación ciudadana en la dirección y control del aparato estatal.

Al aceptar la visión del socialismo europeo de entonces sobre cómo construir el socialismo, la Constitución de 1976, cuya inspiración fundamentalmente lo constituyó la Constitución de 1936 de la Unión Soviética (República de Cuba, 1975), ${ }^{13}$ concibe varios principios de organización y funcionamiento del Estado: forma de Estado republicana, unitaria y democrática, con un sistema de poder popular en niveles nacionales y locales (provincia y municipio) cuyo máximo órgano de poder (no poder legislativo únicamente) en forma asamblearia entrañaba el órgano de mayor representatividad de la soberanía popular; el principio de unidad de poder, mecanismo de los órganos del Estado que lo entendía como unidad política y de trabajo, que combinaba una dirección centralizada con la iniciativa de los poderes de los órganos locales, a partir de la coordinación y fiscalización de sus actividades por los primeros, sin contradicción entre los órganos del Estado ni entre los órganos centrales y locales, sino como unidad de todo el sistema de los órganos estatales como órganos representativos de abajo hacia arriba; centralismo democrático, que entrañaba la electividad de todos los órganos del poder estatal; reconocimiento constitucional al Partido Comunista, como la fuerza dirigente y orientadora de la sociedad y el Estado, y el reconocimiento de organizaciones políticas y de masas en numerus clausus, así como los tipos de propiedad, donde la propiedad estatal convivía con la propiedad del pequeño agricultor, propiedad personal, propiedad cooperativa, y la propiedad de las organizaciones de masas y sociales (Álvarez Tabío, 1988: 239-254).

De este modo, se definió un sistema político con un rechazo marcado de los principios organizativos y funcionales del Estado burgués nacido en 1789, que habían con-

13. En el año 1975, el Departamento de Reproducción del Ministerio de Justicia elaboró un anteproyecto de Constitución concordado con las constituciones de los países socialistas, en el que se compararon los artículos de constituciones socialistas de países como Unión de Repúblicas Socialistas Soviéticas, la República Popular de Albania, la República Popular de Polonia, la República Democrática de Vietnam, la República Popular de Mongolia, la República Socialista Checoslovaca, la República Socialista de Rumanía, la República Democrática Alemana, la Constitución de la República Popular de Bulgaria, la República Popular de Hungría, la República Popular Democrática de Corea, con los artículos del anteproyecto de Constitución cubana con las modificaciones que fueron introducidas por el Buró Político del Comité Central del Partido Comunista de Cuba. Del mismo modo, Fernando Álvarez Tabío reconocería: «Para la elaboración de los preceptos que vamos a analizar de inmediato [se refiere a los artículos del capítulo I, Fundamentos políticos, sociales y económicos del Estado], han servido de guía primordial los logros alcanzados en los órdenes económicos, político y social, por la Revolución, el PCC y el Gobierno Revolucionario, los discursos y opiniones del compañero Fidel Castro y, desde luego, las experiencias de los países que marchan por la vía del socialismo y del comunismo, y los sólidos principios del marxismo-leninismo» (Álvarez Tabío, 1988: 29). 
cebido un sistema de pesos y contrapesos (check and balance) entre los poderes del Estado. La unidad de poder alcanzó una significación de unidad de acción política sin diferenciación estructural, en tanto el sistema de órganos de poder se construyó con ausencia de una divisibilidad real y formal de poder, cuya independencia orgánica no estaba diseñada por límites ni prerrogativas o facultades de naturaleza política contradictorias, por lo cual no se reconoció controles en términos de frenos entre poderes ni mecanismos formales de oposición que controlara al gobierno y le exigiera responsabilidad en torno a posibles alternativas políticas.

Las facultades generales de legislar y ejecutar se encargaron a un tipo de poder asambleario superior (Asamblea Nacional del Poder Popular), además de ser el único intérprete de la Constitución (Constitución de la República de Cuba, 1976: artículo 70), ${ }^{14}$ cuyo diseño y funcionamiento se convirtió en el eje de las relaciones de poder del aparato estatal. Por esta razón, el resto de los órganos superiores del Estado se le subordinaba a la Asamblea, quien a su vez los elegía, aprobaba o designaba (Constitución de la República de Cuba, 1976: artículo 75), ${ }^{15}$ como lo es el Consejo de Estado -órgano que representa a la Asamblea Nacional entre periodo y periodo de sesiones (Constitución de la República de Cuba, 1976: artículos 89 y 90 $)^{16}$ - y el Consejo de Ministros, el Tribunal Supremo Popular, la Fiscalía General de la República, así la Contraloría General de la República, cuya creación fue en 2009 (Ley de Cuba 107, 2009). En la lógica de este modelo, no había cabida para concebir un control externo al órgano supremo de poder (un Tribunal Constitucional, por ejemplo) como equilibrio entre partes, por lo que la propia Asamblea es la encargada de controlar la constitucionalidad de sus propias leyes (Constitución de la República de Cuba, 1976: artículo 75, letra c). ${ }^{17}$ Con estas características la Constitución de 1976 no estableció el cargo de presidente de República como puede concebirse en los sistemas presidencialistas, sino el cargo de presidente del Consejo de Estado, órgano colegiado de poder (Constitución de la República de Cuba, 1976: artículo 89), quien a su vez era el jefe del Consejo de Ministros, órgano ejecutivo

14. «La Asamblea Nacional del Poder Popular es el único órgano con potestad constituyente y legislativa en la República».

15. Este establece entre las atribuciones de la Asamblea Nacional del Poder Popular las de: «l) elegir al presidente, al primer vicepresidente, a los vicepresidentes, al secretario y a los demás miembros del Consejo de Estado; ll) designar, a propuesta del presidente del Consejo de Estado, al primer vicepresidente, a los vicepresidentes y demás miembros del Consejo de Ministros; ) elegir al presidente, al vicepresidente y a los demás jueces del Tribunal Supremo Popular; n) elegir al fiscal general y a los vicefiscales generales de la República;»

16. El primero señala que «el Consejo de Estado es el órgano de la Asamblea Nacional del Poder Popular que la representa entre uno y otro periodo de sesiones, ejecuta los acuerdos de esta y cumple las demás funciones que la Constitución le atribuye. Tiene carácter colegiado y, a los fines nacionales e internacionales, ostenta la suprema representación del Estado cubano». Mientras el segundo indica que «son atribuciones del Consejo de Estado: c) dictar decretos-leyes, entre uno y otro periodo de sesiones de la Asamblea Nacional del Poder Popular».

17. Señala: «c) decidir acerca de la constitucionalidad de las leyes, decretos-leyes, decretos y demás disposiciones generales». 
del Estado, de modo que se constituye en el titular del Estado y del gobierno la misma persona (Constitución de la República de Cuba, 1976: artículos 74 párrafo segundo y 93 inciso a). ${ }^{18}$

Con el reconocimiento de Cuba como un «Estado socialista de obreros y campesinos y demás trabajadores manuales e intelectuales» en la Constitución de 1976, y luego de la reforma del 1992 como un "Estado socialista de trabajadores», no se reconoció el pluralismo partidista en el sistema político con la existencia del Partido Comunista de Cuba como el único partido reconocido constitucionalmente (Constitución de la República de Cuba, 1976: artículo 5). ${ }^{19}$ El principio de unidad de poder cimentó una estructura que en términos de funcionabilidad potenció la acción política de los órganos de poder sin la representación de un pluralismo partidista en mayoría y minorías ni formas parlamentarias que institucionalizaran, directa o indirecta, la oposición política. No obstante, se reconocieron las instituciones de la rendición de cuentas y la revocación entre los principios organizativos y de funcionamiento de todos los órganos estatales (Constitución de la República de Cuba, 1976: artículo 66), pese a que hasta la reforma constitucional de $1992,{ }^{20}$ el pueblo solo elegía directamente a los delegados a las asambleas municipales (Constitución de la República de Cuba, 1976: artículo 138, párrafo 2$),{ }_{,}^{21}$ los que a su vez elegían a los delegados de las asambleas provinciales y a los diputados a la Asamblea Nacional (Constitución de la República de Cuba, 1976: artículos 69 y 139). ${ }^{22}$

En el año 1992, la Constitución fue sometida a una profunda reforma como parte de un programa de distensión política y económica a lo interno del modelo socialista cubano, que reimpulsó de forma global la revisión de elementos ideológicos rígidos de la doctrina «marxista-leninista» aceptada como doctrina oficial del Estado desde 1976, y que habían servido de frenos en la forma de entender los procesos de transformaciones socialistas (Escalona Regueira, 1992: 7; Prieto Valdés, 2004: 47 y ss.; Pérez Hernández y Hernández Ruiz, 2004: 99-100; Poyal Costa, 1995: 425-444). ${ }^{23}$ Las problemáticas a enca-

18. El primero expresa: «El presidente del Consejo de Estado es jefe de Estado y jefe de Gobierno;» mientras que el segundo dice: «Las atribuciones del presidente del Consejo de Estado y jefe de Gobierno son las siguientes: a) representar al Estado y al Gobierno y dirigir su política general».

19. «El Partido Comunista de Cuba, martiano y marxista-leninista, vanguardia organizada de la nación cubana, es la fuerza dirigente superior de la sociedad y del Estado, que organiza y orienta los esfuerzos comunes hacia los altos fines de la construcción del socialismo y el avance hacia la sociedad comunista.»

20. La Ley 1305 de 7 de julio de 1976, que sería derogada con excepción de algunos capítulos por la Ley 37 de 15 de agosto de 1982, que sería derogada posteriormente por la Ley 72 de 1992.

21. «Los delegados a las Asambleas Municipales se eligen por circunscripciones electorales previamente determinadas».

22. El primero indica que «la Asamblea Nacional del Poder Popular se compone de diputados elegidos por las Asambleas Municipales del Poder Popular en la forma y en la proporción que determina la ley», mientras que el segundo expresa que «las asambleas municipales eligen, a través del voto secreto, a los delegados a las Asambleas Provinciales del Poder Popular»

23. Los autores citados abordan las consecuencias normativas de la nueva situación política y económica en Cuba. 
rar pondrían el centro de discusiones en un grupo de temáticas no tomadas en cuenta por la ideología de tipo estalinista: el rol del mercado en una economía planificada, la relación entre Estado y el Partido, fórmulas para destacar al Estado de determinadas áreas económica de tipo no fundamentales, etcétera.

Desde el punto de vista organizativo, pese a no reconocer expresamente los principios de unidad de poder, centralismo democrático y democracia socialista, estos quedaron fundidos en los "principios de la democracia socialista» sobre los cuales los órganos del Estado se integraban y desarrollaban su actividad, según el artículo 68 después de la Reforma Constitucional de 1992 (Constitución de la República de Cuba, 1976: artículo 66). ${ }^{24}$ De esta manera, la electividad siguió constituyendo un principio básico del sistema político cubano, que partía de la Constitución de la República de Cuba de 1976, artículo $3,{ }^{25}$ y se reforzaba en la Constitución de la República de Cuba del mismo año, artículo $68 .^{26}$

En este contexto, la Ley Electoral 72 de 1992, que sustituye a la Ley Electoral 1305 de 7 de julio de 1976, reguló un ciclo de elecciones en Cuba de carácter general cada cinco años para elegir delegados a las asambleas municipales, provinciales y diputados a la Asamblea Nacional, y una de elección parcial cada dos años y medio para la elección de los delegados a la Asamblea Municipal mediante voto voluntario, libre, directo y secreto. Para las asambleas municipales el modelo contempla circunscripciones que se dividen en áreas de nominación, de las cuales puede resultar electo un solo candidato entre una cifra mínima de dos y de ocho como máxima en un sistema de representación proporcional de acuerdo con la elección de candidatos en correspondencia con una cifra de población determinada (Ley de Cuba 72, 1992: artículos 78 a 84). En este ámbito se materializa en alto grado los rasgos de democracia directa en la nominación por asamblea de vecinos y en la elección de los delegados a las asambleas municipales del poder popular, máximo órgano de poder en el territorio.

En cuanto a la elección de los delegados a las asambleas provinciales y diputados a la Asamblea Nacional, prevé que se elaboren proposiciones de precandidatos, que son elaboradas y presentadas para su consideración a las Asambleas Municipales del Poder Popular por las comisiones de candidaturas. Una particularidad de esta nueva ley es que el Partido Comunista de Cuba pierde su significación electoral en la conformación de las comisiones de candidaturas a nivel nacional, provincial y municipal, y las inte-

24. En su texto inicial regulaba: «Los órganos del Estado se integran, funcionan y desarrollan su actividad sobre la base de los principios de la democracia socialista, la unidad de poder y el centralismo democrático».

25. «En la República de Cuba la soberanía reside en el pueblo, del cual dimana todo el poder del Estado. Ese poder es ejercido directamente o por medio de las Asambleas del Poder Popular y demás órganos del Estado que de ellos se derivan, en la forma y según las normas fijadas por la Constitución».

26. El artículo 68 regula los principios de organización y funcionamiento de los órganos estatales, a saber: la electividad y renovabilidad de todos los órganos representativos de poder; el control de la actividad por las masas populares de los órganos estatales, diputados, delegados y funcionarios; la rendición de cuentas y la revocación de los elegidos, etcétera. 
grarían desde entonces la Central de Trabajadores de Cuba, los Comités de Defensa de la Revolución, la Federación de Mujeres Cubanas, la Asociación Nacional de Agricultores Pequeños, la Federación Estudiantil Universitaria y la Federación de Estudiantes de la Enseñanza Media, designados por las direcciones nacionales, provinciales y municipales respectivas a solicitud de las comisiones electorales nacional, provinciales y municipales, presididas por un representante de la Central de Trabajadores de Cuba (Ley de Cuba 72, 1992: artículo 68).

En Cuba, se entiende que las organizaciones reconocidas en el artículo 7 de la Constitución surgidas en el proceso histórico de las luchas del pueblo cubano, representan los intereses específicos e incorporan a su membresía las tareas de edificación, consolidación y defensa de la sociedad socialista. Estos se fueron creando en las condiciones históricas y sociales de la construcción de la nueva sociedad, y se desarrollaron estrechamente vinculadas a las masas que se fueron agrupando en poderosas organizaciones por sectores (Cañizares Abeledo, 1998: 266).

En este sentido, las comisiones de candidaturas provinciales y nacional preparan las proposiciones de precandidatos a delegados y a diputados a las asambleas provinciales y nacional respectivamente, teniendo en cuenta las propuestas de las comisiones de candidaturas municipales y las que ellas mismas elaboran. Para ello, además no solo deberán consultar el parecer de cuantas instituciones, organizaciones y centros de trabajo estimen pertinentes tanto como sea posible, sino también los criterios de los delegados a las Asambleas Municipales del Poder Popular (Ley de Cuba 72, 1992: artículos 85 y 87). El número de delegados a las Asambleas Municipales del Poder Popular que sean seleccionados como precandidatos a delegados a las asambleas provinciales y a diputados a la Asamblea Nacional del Poder Popular no debe exceder de un $50 \%$ del total de los precandidatos propuestos para dichos cargos en cada municipio (Ley de Cuba 72, 1992: artículo 87).

La lógica del proceso continúa en el sentido de que, una vez aprobadas por las comisiones de candidaturas provinciales y nacional, las proposiciones de precandidatos a delegados y a diputados a las asambleas provinciales y nacional del Poder Popular, estas se remiten a las correspondientes comisiones electorales provinciales y nacional para que comprueben que los propuestos reúnen los requisitos exigidos por la ley para ocupar esos cargos. Las comisiones de candidaturas provinciales y nacional, cumplido este trámite, envían las proposiciones a las correspondientes comisiones de candidaturas municipales para su presentación a las Asambleas Municipales del Poder Popular respectivas (Ley de Cuba 72, 1992: artículo 89). ${ }^{27}$

La nominación para la Asamblea Provincial y Nacional corre a cuenta de las asam-

27. Establece que «el número de proposiciones de precandidatos a delegados a las Asambleas Provinciales y a diputados a la Asamblea Nacional del Poder Popular que remitirán las comisiones de candidaturas provinciales y nacional a las comisiones de candidaturas municipales, debe ser una cantidad no menor del doble de la cifra de delegados de la Asamblea Provincial y de diputados a la Asamblea Nacional del Poder Popular que debe elegir cada municipio». 
bleas municipales del Poder Popular, previa presentación de precandidatos por las Comisiones de Candidaturas, quienes tienen la facultad de aprobar o rechazar a uno o a todos los precandidatos, en cuyo caso las comisiones de candidaturas deberán presentar otro u otros precandidatos a la decisión de la correspondiente Asamblea Municipal del Poder Popular (Ley de Cuba 72, 1992: artículos 92 y 93) ${ }^{28}$ En este sentido, la elección para la Asamblea Provincial y Nacional se realiza de manera directa por el electorado después de la reforma constitucional de 1992, donde no se permite agregar otros candidatos en la boleta (Oficina Nacional de Estadística de Cuba, 2011). ${ }^{29}$

Posteriormente, en 2002 la Constitución fue sometida a otra reforma, pero en esta ocasión con la sola intención de introducir una disposición especial conocida como «cláusula de intangibilidad» o «cláusula pétrea», que expresaba la «irrevocabilidad» del carácter socialista y el sistema político y social contenidos en la Constitución. Ello fue provocado por las continuas amenazas y exigencias del gobierno del entonces presidente de Estados Unidos, George W. Bush, que condujo a una política de abierta confrontación con la revolución cubana para un cambio de régimen político en la isla. Esta cláusula no implica, a mi modo de ver, que el poder constituyente originario, el pueblo de Cuba, queda limitado de aprobar una Constitución con un signo ideológico y político diferente, sino que establece una limitación para el poder constituyente derivado, en este caso para la Asamblea Nacional del Poder Popular, que según el artículo 70 de la Constitución de 1976 es el órgano con potestad constituyente.

\section{El modelo político en la Constitución de 2019: ¿ruptura o continuidad?}

La Constitución de 2019 tiene causa en varias razones de índole económica, política y social. En primer lugar, se destacan las profundas transformaciones en lo económico y social en el contexto actual cubano que no encuentran amparo constitucional en el texto aprobado en 1976 y reformado en 1978, 1992 y 2002. Mutaciones importantes en el ámbito económico a partir de los lineamientos que en esta esfera adoptó el Partido Comunista (Partido Comunista de Cuba, 2011) y que suponen un verdadero reto por sus implicaciones en algunos preceptos del texto constitucional y en el desenvolvimiento de la sociedad cubana. En segundo lugar, el relevo en la dirección política del país hacia una generación más joven de dirigentes que supone nuevos liderazgos y modos de

28. El segundo párrafo del mencionado artículo 92 establece que «cada Asamblea Municipal nomina igual número de candidatos a delegados a la Asamblea Provincial y a diputados a la Asamblea Nacional del Poder Popular, que aquellos que le corresponda elegir al municipio». Por su parte, el artículo 93 establece que «en cada municipio, hasta un cincuenta (50) porciento del total de candidatos a delegados a la Asamblea Provincial y de candidatos a diputados a la Asamblea Nacional del Poder Popular podrán seleccionarse de entre los delegados a la Asamblea Municipal del Poder Popular».

29. La inscripción tiene carácter universal, automática y gratuita de los electores, y el candidato se elige si obtiene más del 50 \% de los votos válidos emitidos, además de que no se permite el voto a los ciudadanos emigrados al momento de la votación. Los porcentajes de participación a estas elecciones muestran niveles por encima del $95 \%$ de los electores desde 1976 hasta 2010. 
hacer políticas, la necesidad de incorporar órganos superiores de poder que funcionan en la actualidad solo con tutela legal como la Contraloría General de la República, así como la necesidad de atemperar los preceptos constitucionales ante los nuevos escenarios sociales como puede ser cubanos con dos ciudadanías, las demandas de parejas homosexuales para el reconocimiento del matrimonio igualitario, una diversidad social antes no existente, exigen cambios en la actual regulación constitucional. Habría que agregar las transformaciones políticas en el ámbito internacional de procesos progresistas, fundamentalmente en Latinoamérica, que han llevado sus cauces políticos por vías constitucionales y han supuesto avances enormes en el reconocimiento y protección de derechos humanos que no han podido quedar indiferentes a un modelo que buscar renovarse e insertarse con más fuerza en el sistema internacional.

En cuanto al modelo político se puede afirmar que los fundamentos esenciales que lo caracterizaron en la Constitución de 1976 están vigentes en esta nueva constitución, cuyo carácter socialista se reconoce otra vez como «irrevocable» (Constitución de la República de Cuba, 2019: artículos 4 y 229). El reconocimiento de que «Cuba es un Estado socialista de derecho y justicia social, democrático, independiente y soberano, organizado con todos y para el bien de todos» (Constitución de la República de Cuba, 2019: artículo 1) y que «la soberanía reside intransferiblemente en el pueblo, del cual dimana todo el poder del Estado», la cual «ejerce directamente o por medio de las asambleas del Poder Popular y demás órganos del Estado que de ellas se derivan» (Constitución de la República de Cuba, 2019: artículo 3), viene acompañado del rechazo a la pluralidad de partidos políticos y de la consolidación del unipartidismo, donde el Partido Comunista de Cuba continúa siendo la fuerza política dirigente de la sociedad y el Estado con un gran peso en la vida política (Constitución de la República de Cuba, 2019: artículo 5). ${ }^{30}$

De igual forma, se reconoce a la Unión de Jóvenes Comunistas como la «organización de vanguardia de la juventud cubana», que cuenta con el reconocimiento y el estímulo del Estado y «contribuye a la formación de las más jóvenes generaciones en los principios revolucionarios y éticos de nuestra sociedad, y promueve su participación en la edificación del socialismo» (Constitución de la República de Cuba, 2019: artículo 6). En un mismo sentido establece que el Estado «reconoce y estimula a las organizaciones de masas y sociales, que agrupan en su seno a distintos sectores de la población, representan sus intereses específicos y los incorporan a las tareas de la edificación, consolidación y defensa de la sociedad socialista» (Constitución de la República de Cuba, 2019: artículo 14), que para el caso son la Central de Trabajadores de Cuba, los Comités

30. «Artículo 5. El Partido Comunista de Cuba, único, martiano, fidelista, marxista y leninista, vanguardia organizada de la nación cubana, sustentado en su carácter democrático y la permanente vinculación con el pueblo, es la fuerza política dirigente superior de la sociedad y del Estado. Organiza y orienta los esfuerzos comunes en la construcción del socialismo y el avance hacia la sociedad comunista. Trabaja por preservar y fortalecer la unidad patriótica de los cubanos y por desarrollar valores éticos, morales y cívicos». 
de Defensa de la Revolución, la Federación de Mujeres Cubanas, la Asociación Nacional de Agricultores Pequeños, la Federación Estudiantil Universitaria y la Federación de Estudiantes de la Enseñanza Media.

El modelo de esta forma deja intacta la concepción ideológica que abrazó la Constitución de 1976 sobre el papel del Partido Comunista, el papel de los sindicatos, y del resto de las organizaciones de masas y sociales en el escenario político socialista y que tiene sus antecedentes en la Unión Soviética. La concepción de Lenin, reproducida por los principales teóricos del Partido Comunista de Cuba (Carneado, 1974: 7-15; Carneado, 1974: 16-33; García Gallo, 1974: 34-45; Guerra Hidalgo, 1974: 46-53; Chávez, 1974: 62-67), ${ }^{31}$ partía de que estos debían ser organizaciones no estatales en la realización de la «dictadura del proletariado», como organización que agrupaban la totalidad de los obreros pero de carácter secundario en importancia con respecto al Estado y el Partido, esto es, entre el Partido y el poder del Estado como organismos imprescindibles para cumplir las funciones estatales.

En 1975, Fidel Castro, el líder de la Revolución cubana, acogió esta interpretación en el Informe del Primer Congreso del Partido Comunista de Cuba:

En las organizaciones de masas y sociales tiene nuestra Revolución un poderoso e inagotable caudal de energía política y revolucionaria. Ellas son el enlace que asegura la más estrecha vinculación del Partido con las amplias masas. Ellas son la garantía de su influencia educativa, orientadora y movilizativa. Ellas constituyen la gran escuela en que se desarrolla la conciencia de millones y millones de trabajadores, hombres y mujeres, viejos, jóvenes y niños. Ellas son la fragua donde se forjan incontables cuadros y militantes de la Revolución. Ellas permiten a la dirección de nuestro Partido conocer el sentir, los problemas y las opiniones de cada sector de la población, cuyos intereses específicos defienden y representan (Castro, 1975: 162-163).

Esta concepción es replicada en los Estatutos del Partido Comunista de Cuba vigentes hasta el momento, cuando en su capítulo VIII titulado «El Partido, la Unión de Jóvenes Comunistas y las Organizaciones de masas y sociales» expone en su artículo 6o que:

El partido orienta y dirige el trabajo de las organizaciones de masas y sociales sobre la base del principio del acatamiento libre y consciente de su papel dirigente y en virtud de la influencia de sus militantes en el seno de las masas y con reconocimiento de la independencia orgánica y la autonomía de dichas organizaciones. El método de dirección y orientación del partido con respecto a esas organizaciones es el de la más amplia y democrática discusión, el del razonamiento y el convencimiento de la línea y acuerdos del partido, el del respeto a la autonomía de esas organizaciones y a los intereses de los sectores de la población que ellas representan (Partido Comunista de Cuba, 2013: 32).

31. Autores citados a modo de ejemplo. 
De este modo, al margen de las instituciones religiosas y asociaciones fraternales (Constitución de la República de Cuba, 2019: artículo 15), ${ }^{32}$ así como de otras asociaciones que se constituyan con personalidad jurídica propia al amparo de la Ley de Asociaciones de Cuba (Ley de Cuba 54, 1985: artículo 2), ${ }^{33}$ el modelo no admite la existencia de otras organizaciones de carácter políticas en el escenario cubano. De hecho, aquellas que se han constituido hasta el presente guardan estrechas relaciones de convivencia con el Estado, en la realización de los fines y objeto por el cual se constituyeron. Aquellas que puedan surgir con fines exclusivamente políticos, además de no encontrar amparo constitucional ni legal, pueden estar incurriendo en el delito de «Asociaciones, Reuniones y Manifestaciones Ilícitas», previsto y sancionado en la Ley 62 de Cuba (1987: artículo 208) y en el Código Penal actualmente vigente.

En cuanto a la estructuración de los órganos de poder, la Constitución proyecta algunos cambios, pero mantiene los fundamentos esenciales de la anterior. De esta manera, el nuevo texto tuvo como antecedentes el estudio (República de Cuba, 2017: $3)^{34}$ de la Constitución de la República Popular China y de la República Democrática de Vietnam, así como de las que integran el llamando Nuevo Constitucionalismo Latinoamericano, los textos de Venezuela, Ecuador y Bolivia. Sin embargo, al compararse una con otras, no es difícil advertir que, en lo referido a la estructura del poder, asimila la estructura de poder establecida en la Constitución de la República Socialista de Vietnam de 1992..$^{35}$

Hay que insistir que la nueva Constitución no acepta la tripartición de poder como principio estructural en la organización del Estado. La Asamblea Nacional del Poder Popular continúa siendo el órgano supremo de poder del Estado, que representa a todo el pueblo y expresa su voluntad soberana (Constitución de la República de Cuba, 2019: artículo 102). El presidente de República, cargo que reaparece en el escenario político cubano como cargo independiente del Consejo de Estado, si bien asume algunos rasgos propios de un presidencialismo (Constitución de la República de Cuba, 2019: artículo 128), ${ }^{36}$ responde políticamente ante la Asamblea Nacional, le rinde cuenta de

32. La nueva Constitución establece que el Estado reconoce, respeta y garantiza la libertad religiosa y declara que el Estado cubano es laico, donde las instituciones religiosas y asociaciones fraternales están separadas del Estado y todas tienen los mismos derechos y deberes, así como que las distintas creencias y religiones gozan de igual consideración..

33. Denominada «Ley de Asociaciones», establece en su artículo 2 el carácter de las asociaciones que se constituyen al amparo de esa ley, es decir aquellas de carácter científicas o técnicas; culturales y artísticas; deportivas; de amistad y solidaridad; o cualesquiera otras que conforme a la Constitución y a esta ley se propongan fines de interés social.

34. Ver, en específico, la Introducción al análisis del Proyecto de Constitución de la República durante la consulta popular.

35. Ver en especial el Capítulo VI referido a la Asamblea Nacional, especialmente la Constitución de la República Socialista de Vietnam de 1992 en sus artículos 90-91, y el Capítulo VII, en lo atinente al presidente del país, fundamentalmente en la Constitución de la República Socialista de Vietnam de 1992 en sus artículos 101-102.

36. Véase in extenso. 
su gestión (Constitución de la República de Cuba, 2019: artículo 127) y puede ser revocado o sustituido por ella (Constitución de la República de Cuba, 2019: artículo 109, inciso j). Además, la Asamblea Nacional puede revocar total o parcialmente todas las disposiciones jurídicas, generales, entre las que se incluyen los decretos presidenciales (Constitución de la República de Cuba, 2019: artículo 108, inciso h). En este contexto, el presidente de la República no tendrá derecho de veto sobre las disposiciones que se aprueben en la Asamblea Nacional, lo que hubiera constituido la bisagra de un modelo hacia otro, es decir, la ruptura total con el principio de unidad de poder y la vuelta hacia uno de corte presidencialista con diferenciación política y estructural; pero en este caso el presidente solo tendrá entre sus atribuciones refrendar las leyes y decretos-leyes que apruebe la Asamblea Nacional o el Consejo de Estado (Constitución de la República de Cuba, 2019: artículo 128, inciso d).

De este modo, la Asamblea Nacional continúa siendo el centro de gravedad de todo el modelo político cubano, quien elige además del presidente de República y vicepresidente de República, a su presidente, vicepresidente y secretario, y al resto de las personas que conforman el Consejo de Estado; designa, a propuesta del presidente de República, a la figura del primer ministro como cabeza del Consejo de Ministro, así como a los viceprimeros ministros y al resto de los miembros del Consejo de Ministros; al presidente del Tribunal Supremo, los vicepresidentes y los magistrados del Tribunal Supremo, y los jueces legos de esta instancia; al fiscal general y los vicefiscales; al contralor general de la República y a los vicecontralores generales, y al presidente y demás integrantes del Consejo Nacional electoral (Constitución de la República de Cuba, 2019: artículo 109). ${ }^{37}$ Todas estas figuras elegidas o designadas pueden ser revocadas o sustituidas por la Asamblea Nacional (Constitución de la República de Cuba, 2019: artículo 109, inciso j).

En sentido general, la Asamblea Nacional seguirá marcando las pautas generales del funcionamiento del Estado, en la que el resto de los órganos se convierten, pudiera decirse, en sus ejecutores. Es importante resaltar, a modo de ejemplo, que si bien el presidente de República dirige la política exterior, las relaciones con otros Estados, y la relativa a la defensa y seguridad del Estado (Constitución de la República de Cuba, 2019: artículo 128, inciso c), será la Asamblea Nacional la que apruebe los lineamientos generales de la política exterior e interior (Constitución de la República de Cuba, 2019: artículo 108, inciso n). Del mismo modo, la Asamblea Nacional continuará ejerciendo el control de constitucionalidad sobre las leyes, decretos-leyes, decretos presidenciales, decretos, y demás disposiciones generales (Constitución de la República de Cuba, 2019: artículo 108, inciso d), con lo que se renuncia al necesario órgano de control externo a la Asamblea, y se refuerza la idea de órgano supremo, ante lo cual ningún órgano externo puede anular o suspender disposiciones jurídicas que emanen de su seno.

En este sentido, el texto constitucional sigue siendo expresión de una cosmovisión que replica los fundamentos políticos e ideológicos sostenidos hasta el momento por

37. Ver artículo íntegramente. 
el proceso político cubano y que hunde sus raíces en los procesos que representaron la alternatividad política al modelo del liberalismo. Estos fundamentos descansan en el carácter teleológico del propio proceso político del cual el texto constitucional y por tanto la estructuración del poder forman parte, a saber, la búsqueda del comunismo (Constitución de la República de Cuba, 2019: artículo 5) por medio de la unidad de todos sus elementos de la sociedad con el Partido Comunista como vanguardia organizada de la nación y organizador y orientador en esos esfuerzos. Esta razón explica el establecimiento de estructuras de poder que permiten la unidad de acción política y rechace instituciones propias de repúblicas o monarquías parlamentarias que reproduzcan contradicciones entre los órganos de poder, como puede ser entre el Gobierno y el Parlamento, resultante de la existencia de contradicciones políticas partidistas por el poder. Téngase que la Asamblea no verá resquebrajada su supremacía absoluta ante un Gobierno que pueda disolverla y llamar a elecciones anticipadas, propio de modelos parlamentarios.

De esta forma, el establecimiento de un presidente de República, como jefe de Estado, independiente del Consejo de Estado -representativo de la Asamblea entre periodo y periodo de sesiones-, y la figura del primer ministro como jefe de gobierno de la República (Constitución de la República de Cuba, 2019: artículo 140 y ss.) a cargo del órgano máximo ejecutivo y administrativo, y quien es designado por la Asamblea Nacional a propuesta del presidente de República por un periodo de cinco años, provoca cambios importantes en el principio de unidad de poder como principio de organización y funcionamiento de los órganos de Estado, sin que pueda decirse que se abandona del todo, pues su espíritu anima todo el diseño político aunque con algunos matices importantes.

Así, aunque no está consagrado el principio en el texto constitucional en la parte referida a los principios de organización y funcionamiento de los órganos de Estado (Constitución de la República de Cuba, 2019: artículo 101), que con ocasión de la reforma constitucional de 1992 fue sustituido por la expresión integradora de «los principios de la democracia socialista» (Constitución de la República de Cuba, 1976: artículo 68) que retoma el artículo 101 de la actual Constitución, está presente de modo implícito en un diseño estructural del poder que no concibe una estructuración de los órganos del poder en términos de pesos y contrapesos propios de modelos organizados bajo el principio de tripartición de poderes.

Ahora, si tenemos en cuenta que el principio de unidad de poder se caracterizó fundamentalmente por una unidad estructural de acción política que se asoció inicialmente con la identidad entre el jefe de Estado y el de gobierno, y que a su vez presidía el órgano colegiado que representaba a la propia Asamblea Nacional como ente supremo de poder en Cuba, ciertamente en el texto constitucional se provoca un cambio importante del principio de unidad de poder por contar ahora con estructuras de acción política diferenciadas. Pero en todo caso, si se asume que la unidad de poder supone unidad de acción política aunque haya estructuras diferenciadas y con funciones distintas, es impensable o inviable, aun con el establecimiento de un presidente de República y un primer ministro, que ese vínculo estrecho para la actuación y la toma de decisiones 
vaya a desaparecer, ya que el mecanismo para su aseguramiento está previsto: es la Asamblea la que elige y revoca, la que designa y destituye, y los dos titulares nacen de su seno, a los que se suma el papel del Partido Comunista en la dirección superior del Estado, que estará marcando las pautas políticas fundamentales en el funcionamiento del Estado, lo que invita a sostener que la unidad de poder reviste ahora matices de unidad de acción política con diferenciación estructural.

De cualquier modo, la separación del jefe de Estado del Consejo de Estado como órgano permanente de la Asamblea Nacional del Poder Popular, y el establecimiento de que el presidente de la Asamblea Nacional, el vicepresidente y el secretario de la Asamblea Nacional, lo son a su vez del Consejo (Constitución de la República de Cuba, 2019: artículo 121 y ss.), así como la conservación de facultades normativas (Constitución de la República de Cuba, 2019: artículo 122), hace pensar que este órgano pasará a tener una función mucho más activa en el funcionamiento de la Asamblea Nacional (Constitución de la República de Cuba, 2019: artículo 121). ${ }^{38}$

Esta realidad pone en expectativa un futuro perfeccionamiento del funcionamiento de la propia Asamblea Nacional, que ha tenido un papel mucho menos activo que otros órganos superiores derivados de ella $-y$ que se ha traducido en la aprobación en bloque de actos aprobados por estos órganos, incluso de aquellos decretos-leyes aprobados por el Consejo de Estado modificativos de leyes aprobadas por la propia Asamblea Nacional-, y una mayor implicación de los diputados en la creación normativa y en la creación de políticas públicas. Esto debe suponer un replanteo de cómo se integra este órgano (Ley de Cuba 72, 1992: artículo 14), ${ }^{39}$ que tiene en las comisiones de candidaturas reguladas en la Ley Electoral un momento importante, en busca de una mayor presencia de los delegados a las Asambleas Municipales del poder Popular (Ley de Cuba 72, 1992: artículo 93);40 del mismo modo que deben revaluarse las relaciones de los diputados con sus electores, aun cuando se mantiene el carácter no profesional de la política a los diputados a la Asamblea Nacional (Constitución de la República de Cuba, 2019: artículo 115).

Un aspecto a resaltar es que se mantienen los principios de la «democracia socialista» que tiene sus antecedentes en instituciones defendidas por el pensamiento de izquierda de finales del siglo XIX y principios del siglo XX, y se incorporan otros. En este caso, establece en su artículo 101 que los órganos del Estado se integran y desarrollan su actividad sobre el carácter electivo y renovable de todos los órganos representativos de poder; el control por el pueblo de la actividad de los órganos estatales, de sus directivos

38. Este criterio se refuerza al establecer que no pueden integrar el Consejo de Estado los miembros del Consejo de Ministros, ni las máximas autoridades de los órganos judiciales, electorales y de control estatal.

39. «La Asamblea Nacional del Poder Popular estará integrada por diputados elegidos a razón de uno por cada veinte mil (20.00o) habitantes de un municipio, o fracción mayor de diez mil (10.00o), que es su circunscripción electoral».

40. «En cada municipio, hasta un cincuenta porciento del total de candidatos a delegados a la Asamblea Provincial y de candidatos a diputados a la Asamblea Nacional del Poder Popular podrán seleccionarse de entre los delegados a la Asamblea Municipal del Poder Popular». 
y funcionarios, de los diputados y de los delegados; la rendición de cuentas de todos los elegidos como un deber; y el derecho a la revocación de todos los elegidos. De igual modo, establece que los órganos estatales de acuerdo con sus funciones y en el marco de su competencia desarrollan las iniciativas encaminadas al aprovechamiento de los recursos y posibilidades locales y la incorporación de las organizaciones de masas y sociales a su actividad; la obligatoriedad de las disposiciones de los órganos estatales superiores con respecto a los inferiores; la rendición de cuenta de los órganos inferiores ante los superiores; la libertad de discusión, el ejercicio de la crítica y la autocrítica y la subordinación de la minoría a la mayoría rigen en todos los órganos estatales colegiados; y la debida transparencia de los órganos del Estado, sus directivos y funcionarios.

Un campo importante a nivel provincial lo constituyó la desaparición de las Asambleas Provinciales del Poder Popular y el establecimiento de un gobierno provincial del Poder Popular conformado por un gobernador -elegido por los delegados de las asambleas municipales del Poder Popular correspondientes, a propuesta del presidente de la República, por el periodo de cinco años- y un Consejo Provincial (Constitución de la República de Cuba, 2019: artículo 170 y ss.). ${ }^{41}$ En este caso, los consejos provinciales, órganos colegiados y deliberativos, son presididos por el gobernador e integrado por el vicegobernador, los presidentes y vicepresidentes de las asambleas locales del Poder Popular correspondientes y los intendentes municipales. En esta importante restructuración de los órganos de poder hay una clara intención de fortalecer el ámbito municipal del poder popular, para lo que se establecen además con carácter constitucional los derechos de petición y de participación ciudadana en el ámbito local (Constitución de la República de Cuba, 2019: artículo 200 y ss.).

Con respecto a este último aspecto, no es posible desconocer la voluntad del constituyente de introducir mecanismos de democracia directa que amplíen y permitan instrumentar el derecho de todos a participar en el desarrollo y transformación social al nivel más local. Sin embargo, no puede obviarse que el nuevo texto reproduce algunas incongruencias o carencias democráticas: el presidente de República será electo por la Asamblea Nacional y no directamente por el pueblo, y aunque debe esperarse por la ley electoral, es muy posible que el sistema electoral preserve en su funcionamiento una doble posición: para la representación local, más cercana a la base (las asambleas municipales del Poder Popular) un tipo de democracia directa con un fuerte influjo roussoniano -que pasó por los teóricos del socialismo marxistas en la búsqueda de un modelo emancipatorio en lo económico y social-, y para la elección a la Asamblea Nacional, una representación indirecta, cuyos perfiles evocan una relativa irresponsabilidad de los elegidos por cuanto los diputados que no son delegados municipales se pueden elegir incluso por circunscripciones donde ni siquiera se ubica su lugar de residencia o de trabajo.

Se trata, en el caso de los delegados a las asambleas municipales del Poder Popular, de un tipo de democracia directa que no completa todo el contenido revolucionario de

41. Ver artículo 170 y ss. de la Constitución de la República de Cuba de 2019. 
construcción social y política «desde abajo» si el delegado no se convierte en un sujeto político con poder real para organizar y liderar en una localidad la construcción de su realidad, decidida por la «creatividad viva de las masas». Si se limita el delegado a recibir demandas sociales generalmente de contenido no políticas, más bien perfiladas al ámbito de la administración pública, se priva a este espacio de posibilidades de construcción política y de decisión sobre el futuro de la localidad.

En esencia, un modelo superior debe erradicar el desfase entre las voluntades y demandas locales de los electores y los intereses que han de defender los elegidos para la Asamblea Nacional. Los diputados no solo deben responder a un deber general de desarrollar sus labores en beneficio de los «intereses del pueblo», cuyo "contacto con sus electores» solo se refiera a un deber de recepcionar planteamientos, sugerencia y críticas, y «explicar la política del Estado». Los electores de esta forma se convierten en «consumidores» de políticas elaboradas o construidas «desde arriba» y la representación pierde su contenido como vehículo para canalizar las agendas y demandas locales, cuando en realidad es un vínculo que responde a una lógica de representación de «sectores» sobre la lógica de responder directamente a la representación de intereses locales. Sin embargo, en el texto constitucional siguen utilizándose, en el marco de los deberes de los diputados a la Asamblea Nacional del Poder Popular, «mantener vínculo con sus electores», «atender sus planteamientos, sugerencias y críticas» $\mathrm{y}$ «explicarles la política del Estado» (Constitución de la República de Cuba, 2019: artículo 133).

En el ámbito de deberes de los delegados municipales, expresiones como «dar a conocer a la Asamblea Municipal las opiniones, necesidades y dificultades que les trasmitan sus electores», «informar a los electores de la política que sigue la Asamblea Municipal» (Constitución de la República de Cuba, 2019: artículo 195 y ss.), y entre sus derechos, además de participar con voz y voto en las sesiones de la Asamblea, «solicitar información» tanto a los directivos de la Asamblea o las entidades radicadas en su territorio (Constitución de la República de Cuba, 2019: artículo 194 y ss.), en realidad no auguran cambios trascendentales que permitan un vuelco hacia una ciudadanía constructora en lo cotidiano de su realidad política y social.

Habría que apuntar que esta concepción del modelo político cubano coincide con una concepción del modelo económico socialista que basa sus fundamentos en «la propiedad socialista de todo el pueblo sobre los medios fundamentales de producción» y en «la dirección planificada de la economía», pero trata de aminorar los elementos rígidos del sistema con la existencia de un mercado regulado y en los marcos de la planificación económica, así como con el reconocimiento de otros tipos de propiedad, como la propiedad cooperativa, la propiedad mixta, la propiedad de las organizaciones políticas, de masas y sociales, la propiedad privada y propiedad personal. Es decir, un modelo económico que trata de replicar a nivel económico la sincronización del todo y la complementariedad de los elementos no integrados (Constitución de la República de Cuba, 2019: título II). ${ }^{42}$

42. Se encuentra dedicado a los fundamentos económicos del Estado cubano. 
En otros temas también importantes, la nueva Constitución amplía el catálogo de los derechos en una proporción no desdeñable con respecto a la constitución anterior, que ahora aparecen agrupados fundamentalmente en el título $\mathrm{V}$ «Derechos, Deberes y Garantías», junto al capítulo dedicado a «las familias», los «deberes», «los derechos y deberes de los extranjeros» y las «garantías de los derechos». En relación con las garantías de los derechos (Constitución de la República de Cuba, 2019: capítulo VI), ${ }^{43}$ se reconoce el derecho del acceso a los órganos judiciales a fin de obtener una tutela efectiva de sus derechos e intereses legítimos; reconoce como una novedad a nivel constitucional la posibilidad del ciudadano de utilizar métodos alternos de solución de conflictos, así como el principio de debido proceso no solo para el proceso penal, sino también para el ámbito de los procedimientos administrativos; se eleva a rango constitucional la institución del hábeas corpus para aquellos que estuvieran privados de libertad ilegalmente; se reconoce el derecho de toda persona de acceder a sus datos personales en registros, archivos u otras bases de datos e información de carácter público, así como a interesar su no divulgación y obtener su debida corrección, rectificación, modificación, actualización o cancelación; se reitera el derecho de las personas a reclamar y obtener la correspondiente reparación o indemnización ante daño o perjuicio causado indebidamente por directivos, funcionarios y empleados del Estado con motivo del ejercicio de las funciones propias de sus cargos; así como el principio de irretroactividad de las leyes, salvo en materia penal cuando sean favorables a la persona encausada o sancionada, y en las demás leyes, cuando así lo dispongan expresamente, atendiendo a razones de interés social o utilidad pública.

Una novedad también en el ámbito de los derechos en relación con su antecesora lo constituye el artículo 99 dentro del marco de las garantías de los derechos, que establece que toda persona tiene derecho a reclamar ante los tribunales la restitución de los derechos y obtener, de conformidad con la ley, la correspondiente reparación o indemnización cuando se le vulneren los derechos consagrados en esta Constitución y, como consecuencia, sufriera daño o perjuicio por órganos del Estado, sus directivos, funcionarios o empleados, con motivo de la acción u omisión indebida de sus funciones, así como por particulares o por entes no estatales.

Esto supone una judicialización en la protección de los derechos constitucionales mediante un "procedimiento preferente, expedito y concentrado», que parece suponer su viabilidad a través de una Sala de lo Constitucional en el Tribunal Supremo de la República. No obstante, resulta incongruente con el principio de supremacía normativa (Constitución de la República de Cuba, 2019: artículo 7) ${ }^{44}$ y de aplicación directa de la Constitución, que la Constitución exprese para este tipo de garantías que la ley establecerá «aquellos derechos amparados por esta garantía». Las preguntas quedan abiertas

43. Ver íntegramente.

44. «Artículo 7. La Constitución es la norma jurídica suprema del Estado. Todos están obligados a cumplirla. Las disposiciones y actos de los órganos del Estado, sus directivos, funcionarios y empleados, así como de las organizaciones, las entidades y los individuos se ajustan a lo que esta dispone.» 
entonces. ¿Qué derechos garantizados en esa Constitución no serán garantizados judicialmente? ¿Habrá tenido causa esta inclusión en un rechazo a que aquellos derechos de carácter social y económico puedan ser justiciables? ¿No podrá un tribunal aplicar los preceptos constitucionales para brindar protección judicial de los derechos que una disposición jurídica de inferior jerarquía excluya de su protección? Habrá que esperar para conocer las respuestas a estas interrogantes.

\section{Conclusión}

La pregunta sobre si la Constitución de 2019 constituye una continuidad o una ruptura del modelo político adoptado en la Constitución de 1976, y que a su vez se inspira en el modelo político establecido en la Constitución soviética de 1936, se ha ido contestando a lo largo de este trabajo. La aparición de nuevos cargos en la estructura de poder y de una reconfiguración a esta propia estructura no tiene gran impacto en un modelo que conserva los fundamentos políticos y económicos más importantes del modelo anterior. En todo caso, se consolida un modelo que se construye para garantizar la «unidad nacional y el liderazgo del Partido Comunista de Cuba», como se reconoce en el preámbulo de la Constitución, que escapa a un modelo que busca el «consenso» a partir de alternativas políticas.

De cualquier manera, habrá que destacar que la actual Constitución estuvo sometida a un proceso de consulta con el pueblo cubano desde el 13 de agosto de 2018 hasta el mes de diciembre del propio año, que conllevó importantes modificaciones al proyecto de texto constitucional presentado inicialmente a partir de los criterios de los ciudadanos cubanos (Juventud Rebelde, 2009). ${ }^{45}$ En todo caso, los cubanos tuvieron la oportunidad de pronunciarse en referéndum el 24 de febrero de 2019 y ratificaron por amplia mayoría la actual Constitución en medio de una gran campaña política por el voto afirmativo a través de los medios de comunicación. No había que ser un observador experto de la vida política del país para augurar que la Constitución sería aprobada por la mayoría de los ciudadanos convocados a votar ese día en una proporción importante, y tampoco para afirmar que por un tiempo indeterminado continuaría vigente

45. Entre los artículos de la Constitución que más recibieron número de propuestas se encuentran el referido a la institución del matrimonio -hubo un gran número que rechazaron la posibilidad de un matrimonio entre personas del mismo sexo-, la no limitación del periodo de mandato y de la edad límite para ser presidente de República, así como la elección directa del presidente de la República, entre muchas otras. Algunas de estas propuestas no fueron acogidas por la Comisión Redactora del texto, que la presidía el primer secretario del Partido Comunista de Cuba, Raúl Castro Ruz. Ver en este sentido, en lo referido a la institución del matrimonio, la Constitución de la República de Cuba de 2009, más específicamente la disposición especial decimoprimera, que estableció que «atendiendo a los resultados de la Consulta Popular realizada, la Asamblea Nacional del Poder Popular dispondrá, en el plazo de dos años de vigencia de la Constitución, iniciar el proceso de consulta popular y referendo del proyecto de Código de Familia, en el que debe figurar la forma de constituir el matrimonio». Para más información sobre los resultados del proceso de consulta popular, véase https://bit.ly/2Z848Bg. 
en sus líneas fundamentales el modelo político establecido por Revolución cubana en la Constitución de 1976.

\section{Referencias}

Álvarez Tabío, Fernando (1988). Comentarios a la Constitución socialista. La Habana: Pueblo y Educación.

Azcuy, Hugo (2010). Análisis de la Constitución y otros ensayos. La Habana: Instituto Cubano de Investigación Cultural Juan Marinello y Ruth Casa.

BAlibar, Etienne (1977). Sobre la dictadura del proletariado. Madrid: Siglo XXI.

Bertot Triana, Harold (2014). «Reflexiones sobre la participación política en la orientación de un proceso de desalienación social». En Guillermo González Orquera y Yuri Pérez Martínez (coordinadores), Participación política, reflexiones desde el sur (77-104). Quito: Tribunal Contencioso Electoral del Ecuador y Universidad de la Habana.

Blagojevic, Borislav T., W. Czachorski, T. Ionasco, V. Knapp, M.A. Kroutogolov, L. Szabo, L. y V.A. Tocmanov (1971). Introduction aux Droits Socialistas. Budapest: Akadémiai Kiado.

Castro, Fidel (1975). Informe Central del Primero Congreso del Partido Comunista de Cuba. La Habana: Departamento de Orientación Revolucionaria del Comité Central del Partido Comunista de Cuba.

Chejarin, Evgueni (1978). «La URSS, Estado socialista de todo el pueblo». En Ley Fundamental de la Unión de Repúblicas Socialistas Soviéticas (pp. 109-126). Moscú: Progreso.

Escalona Regueira, Juan (1992). «En torno a la Ley de Reforma Constitucional». Revista Cubana de Derecho, (8): 3-12.

Ferrando Badía, Juan (1989). Democracia frente a autocracia. Los tres grandes sistemas políticos. Madrid: Tecnos.

Flores JuberíAs, Carlos (1992). «Modelos de transición y sistemas electorales en la Europa del Este». Revista de Estudios Políticos (Nueva Época), 77: 169-217. Disponible en https://bit.ly/2Z72z6O.

Garcini Guerra, Héctor (1974). «La Constitución de los órganos del poder popular». Revista Cubana de Derecho, 8: 61-8o.

Grigorián, Levón y Yuri Dolgopólov (1979). Fundamentos del derecho estatal soviético. Moscú: Progreso.

Hill, Ronald J. (1972). «Continuity and change in URSS Supreme Soviet Elections». British Journal of Political Science, (2) 1: 47-67. DOI: 10.1017/Sooo7123400008425.

LeHNING, Arthur (2004). Marxismo y anarquismo en la Revolución rusa. Buenos Aires: Utopía Libertaria.

LENIN, Vladimir Ilich (1964). «¿Se sostendrán los bolcheviques en el poder?». En Las tareas inmediatas del aparato estatal soviético. La Habana: Política. 
-. (1976). «La dualidad de poderes». En Obras escogidas en doce tomos. Tomo VI. Moscú: Progreso.

-. (1976b). «Las tareas del proletariado en nuestra revolución». En Obras escogidas en doce tomos. Tomo VI. Moscú: Progreso.

-. (1977). «Proyecto de decreto sobre el derecho de revocación». En Obras escogidas en doce tomos. Tomo VII. Moscú: Progreso.

Marianetti, Benito (1961). La legalidad socialista. Buenos Aires: Fundamentos.

MARX, Karl y Friedrich Engels (s.f.). «La guerra civil en Francia». En Obras escogidas en dos tomos. Moscú: Lenguas Extranjeras.

Montesquieu (1976). El espíritu de las leyes. La Habana: Ciencias Sociales.

Oficina Nacional de Estadística e Información - República de Cuba (2011). Anuario Estadístico de Cuba 2010, Proceso Electoral en Cuba, Edición 2011. La Habana: Oficina Nacional de Estadística e Información - República de Cuba.

Partido Comunista de Cuba (2011). «Lineamientos de la Política Económica y Social del Partido y la Revolución, aprobados por el VI Congreso del Partido Comunista de Cuba (Resolución del VI Congreso del Partido Comunista de Cuba de fecha 18 de abril del 2011) y por Acuerdo VII - 61 de fecha 1 de agosto del año 2011, VII Legislatura de la Asamblea Nacional del Poder Popular». Gaceta Oficial de la República de Cuba, (111) 28.

-. (2013). Estatutos del Partido Comunista de Cuba. Con las modificaciones aprobadas en el V Pleno del Comité Central por acuerdo de la primera Conferencia nacional del Partido. Diciembre de 2012. La Habana: Política.

Peraza Chapeau, José (1975). «El sistema electoral y el derecho electoral en los países socialistas». Revista Cubana de Derecho, (4), 10: 189-206.

Pérez Hernández, Lissette y José Antonio Hernández Ruiz (2004). «Apuntes sobre la propiedad, desde el punto de vista constitucional». En Lissette Pérez Hernández y Martha Prieto Valdés (compiladoras), Temas de derecho constitucional cubano (pp. 91-102). La Habana: Félix Varela.

Ponomariov, Borís Nikoláyevich (s.f.). Historia del Partido Comunista de la Unión Soviética. Moscú: Progreso.

Poyal Costa, Ana, (1995). «La Reforma Constitucional cubana (12-6-92) y la Nueva Ley Electoral (72/92)». Revista de Derecho Político, (39): 425-444. Disponible en https://bit.ly/30J1DWG.

Prieto VAldÉs, Martha (2004). «La reforma a la Constitución cubana de 1976». En Lissette Pérez Hernández y Martha Prieto Valdés (compiladoras), Temas de derecho constitucional cubano (pp. 45-50). La Habana: Félix Varela.

-. (1959). Ley Fundamental de la República, con notas de estudio comparativo respecto a la Constitución de 1940 y en apéndice, las leyes del Ejército Rebelde dictadas en la Sierra Maestra, sobre inhabilitación política y reforma agraria, II (Cuaderno Extraordinario). 2. ${ }^{a}$ ed. La Habana: Lex. 
RepúbliCa de Cuba (1975). Anteproyecto de Constitución concordado con las constituciones de los países socialistas. La Habana: Departamento de Reproducción del Ministerio de Justicia.

-. (2017). Proyecto de Constitución de la República de Cuba. La Habana: Empresa de Artes Gráficas Federico Engels.

SÁnChez VÁzquez, Adolfo (2006). Entre la realidad y la utopía. La Habana: Ciencias Sociales.

Shajnazárov, Gueorgui (1984). «El Partido y el Estado». En Compendio de lecturas complementarias para el estudio del derecho constitucional (pp. 357-379). La Habana: Ministerio de Justicia.

ZASLAVSKY, Víctor y Robert J. Brym (1978). «The functions of elections in the USSR». Soviet Studies, (30) 3: 362-371. Disponible en https://bit.ly/2XZmlom.

\section{Sobre el autor}

Harold Bertot Triana es licenciado en Derecho (2013) y máster en Derecho Constitucional y Administrativo (2017) por la Facultad de Derecho de la Universidad de la Habana. Se desempeña como profesor e investigador del Centro de Estudios Hemisféricos y sobre Estados Unidos. Su correo electrónico eshbertottriana@gmail.com. iD http://orcid.org/0000-0003-0737-4710. 